\title{
Ferdinand Tönnies (1855-1936). Vida y sociología. Ana Isabel Erdozáin. Madrid: CIS, 2015
}

\author{
Marc Grau-Grau \\ Harvard Kennedy School. Universitat Internacional de Catalunya \\ Marc_Grau-Grau@hks.harvard.edu \\ mgraug@uic.es
}

Erdozáin, con su obra, cumple un doble objetivo: genera un oasis en el "desértico ámbito tönnesiano" en España, y cose, suavemente, sin prisas y con un excelentísimo cuidado, la vida y contribución académica y político-social del Néstor de la sociología alemana. Recupera un clásico olvidado, y nos recuerda que la sociología es artesanía.

Para llegar a tal fin, y para aproximarse de un modo disciplinado a la vida y sociología de Ferdinand Tönnies, la autora emplea dos vías metodológicas: la metodología de la historia intelectual, y la metodología biográfica. A partir de este riguroso ejercicio intelectual, se estudian no sólo las obras del sociólogo frisón, así como sus intercambios epistolares que son básicos para comprender su itinerario, frustración y nobleza, sino también, como sus experiencias en su entorno familiar, cultural, intelectual y socio-cultural determinan su modo de pensar, teorizar y actuar.

El resultado son cinco grandes etapas del itinerario vital-intelectual de Tönnies -Formación escolar y universitaria (1855-1877); Primeros escritos (1877-1887); La difícil carrera académica y los estudios empíricos (1887-1908); Desarrollo de la teoría sociológica y activa participación en la conformación de la sociología como disciplina científica (1908-1930); Últimas obras, compromiso práctico y su expulsión académica (1930-1936) que junto con la introducción, la conclusión, y el nada desdeñable prólogo del profesor Almaraz, forman los siete capítulos de este libro de 491 páginas con más de mil notas de pie de página, que repasaremos a continuación.
Una vez leída la introducción, donde la autora justifica la necesidad de una aproximación a Tönnies, junto con la presentación de los métodos usados y fuentes consultados, el lector se adentra en la primera etapa (1855-1877) del itinerario vital de Tönnies, que compone el segundo capítulo, y que es clave para comprender la realidad comunitaria en la que creció. Ferdinand Tönnies nació en 1855 en una floreciente casa de labranza en la península de Eiderstedt, actual Alemania, pero bajo la corona danesa en aquel tiempo. Su contacto con la tierra, una relación muy cercana con los criados, la capacidad de la granja familiar de autoabastecerse y hablar una lengua local, frisón y bajo alemán, le ayudaron a incorporar de muy pequeño la importancia de la comunidad. Aprendió a leer con una criada, y debido a su capacidad intelectual y no-necesidad de dedicarse a tareas físicas, se convirtió precozmente en una gran amante de la lectura. A sus 10 años de edad, la familia decide moverse a la vecina ciudad de Husum para beneficiar la educación de sus hijos. Durante los años escolares, Tönnies observa desde lejos dos grandes procesos: la industrialización, y la unificación con Prusia.

Esta primera etapa vital-intelectual finaliza con sus estudios universitarios, que debido a la completa libertad de elección por parte de su padre, facilita su formación completamente interdisciplinar: filosofía, historia alemana, historia griega, arqueología, o mitología entre otros, en las universidades de Jena, Leipzig, Bonn o Berlín. Será precisamente en esta última ciudad, donde conocerá a Friedrich Paulsen, con quien mantendrá 
una amistad profunda durante 30 años. En 1877, finaliza su tesis doctoral "Sobre la cuestión de las especies según el Dios Ammón". Esta etapa rica en formación, el sociólogo frisón experimenta también desmoronamientos físicos y psíquicos que le obligan a refugiarse temporalmente en su tierra natal.

La segunda etapa vital-intelectual sabiamente escogida por Erdozáin, es la que transcurre entre la finalización de su tesis doctoral (1877) y la publicación de la que será su gran obra: Gemeinschaft und Gesellchaft (1887). Son diez años dedicados a estudios y lecturas de modo privado, asesorado por su gran amigo Paulsen. En estos años de incubación se interesa principalmente por la época Contemporánea, y las "cuestiones sociales", así como por la filosofía moderna, la economía y la política. Viaja diez semanas a Londres, para profundizar el estudio sobre Hobbes, por quien tendría una fascinación hasta sus últimos días, y observa de primera mano, la pobreza infantil, el desorbitado afán de lucro de la burguesía, y, en definitiva, las consecuencias negativas del rápido proceso de industrialización. Durante este período, se prepara también por la habilitación de cátedra, posición que no obtendrá hasta los 54 años. Esta falta de reconocimientos, junto con sus dolores de cabeza y añoranza del hogar, disminuyen su falta de confianza.

Este tercer capítulo, que además expone sus primeras clases como catedrático habilitado pero sin titularidad en la Universidad de Kiel, universidad donde hoy se encuentra la autora del libro, es imprescindible ya que se presenta el teorema comunitario-societario, siendo la aportación más relevante de Tönnies. Él, como los principales clásicos de la sociología (Spencer, Simmel, Weber 0 Durkheim) juega con una formulación dicotómica, en su caso Comunidad y Sociedad, para comprender la realidad social. Erdozáin dedica un excurso de más de casi cincuenta páginas a analizar de un modo profundo la teoría comunitario-societaria tönnesiano. En el excurso, se desarrolla la teoría de voluntad, influenciada por Hobbes, Spinoza y Schopenhauer, presentado el concepto de voluntad esencial (Wesenwille) y la voluntad arbitraria (Kürville), que definirán respectivamente a la Comunidad (Gemeinschaft) y a la Sociedad (Gesellschaft). La autora realiza también un esfuerzo importante en distinguir la Gemeinschaft y Gesellschaft, como conceptos normales, que tiene la función de facilitar el manejo, ordenación y dominio del conocimiento experimental, y la Gemeinschaft y Gesellschaft como formas culturales empíricas, con las que el sociológico frisón obtuvo más críticas. Otra gran crítica que repasa Erdozáin, es la supuesta preferencia de Tönnies hacia la Comunidad. Es cierto que Tönnies observa como el hombre pierde la forma de vida comunitaria, regida por una voluntad esencial, en favor de una vida moderna, conducida por una voluntad arbitraria. No obstante, la autora destaca que Tönnies no merece el adjetivo de romántico, y justica la no supuesta preferencia comunitaria del autor.

Con la finalización de su obra en 1887, después de 8 años de arduo trabajo, se cierra la segunda etapa vital-intelectual del sociólogo, y se abre la tercera, formando el cuarto capítulo del libro (1887-1908: La difícil carrera académica y los estudios empíricos). Esta fase se inicia con la fría acogida de su libro. Pocas eran las voces que destacaban la importancia de su obra, a parte de una recensión de su querido amigo Paulsen. Paulsen, en sus fluidos intercambios epistolares, critica la falta de estilo en la obra, así como su pesimismo hacia la Gesel/schaft. Fueron años duros para Tönnies, no llegaba su reconocimiento, no consiguió la ansiada plaza de catedrático que se esfumó de nuevo en 1889 , y no podía dar a sus hijos pequeños más que una pequeña vivienda de alquiler en Hamburgo, con poca luz. Sintió de forma aún más fuerte el extrañamiento y el anonimato. En Hamburgo, sigue observando el mismo fenómeno que observó en Londres: explotación infantil, explotación de la mujer, afán de logro, y falta de consideración hacia la viudedad, maternidad y lactancia.

Durante estos años, no obstante, el sociólogo recupera su viejo deseo de realizar sus propios estudios empíricos sobre criminalidad y delincuencia, estudios que no crean escuela, y reciben más críticas que alabanzas. Dedica tiempo también a sus monografías sobre Hobbes y Nietsche. Con el cambio de siglo, parecen llegar las buenas noticas, en 1901 se muda a la pequeña ciudad de Eutin, donde podrá dar a sus hijos un hogar con espacio y tierra alrededor. Según Erdozáin, estos fueron segura- 
mente los años más felices de Tönnies. Se suma la relación fluida con otros miembros fundadores de la sociología como disciplina en Alemania, como son Sombart, Weber y Simmel. En 1904 le invitan en un congreso en St. Louis, Estados Unidos, donde acude con Weber, y presenta su ponencia "The present problem of social structure" que sería publicado el siguiente año en American Journal of Sociology. Finalmente, en 1908, con 54 años de edad, le ofrecen la soñada plaza de catedrático. Siente no poder compartir la noticia con su querido amigo Paulsen, que murió en agosto del mismo año. La dedicación de Erdozáin a comprender las alegrías y frustraciones, a través del intercambio epistolar con sus amigos, maestros y colegas, es fundamental para comprender la profunda vida de Tönnies, y una de las grandes riquezas del libro.

La cuarta etapa, que podríamos considerar de alta madurez, y que la autora limita del 1908 a 1930, destaca por la fundación de la Sociedad Alemana de Sociología (Deutsche Gesellschaft für Soziologie) en 1909, de la cual Tönnies fue presidente hasta 1933, y que fue clave para la conformación de la sociología como disciplina científica. Esta etapa caracterizada por funestos sucesos en la historia alemana (derrota en la primera Guerra Mundial, humillante acuerdo de Versalles, hiperinflación durante la república de Weimar, y gran depresión que llevó a los nacionalsocialistas al poder) pone de relieve la coherencia y el rigor moral tönnesiano. A lo largo de estos años, el autor publica monografías sobre el progreso y la modernidad, así como su autobiografía (1922), y una recopilación de artículos, recensiones, ponencias y críticas sociológicas publicadas en tres volúmenes entre 1925 y 1929. Aunque son años oscuros, Tönnies también escribe una monografía con un mensaje esperanzador, titulado la Buena Nueva (Neue Botschaft), que no verá la luz en vida del autor. Erdozáin también destaca el nombramiento de miembro de honor de la Societas Spinoziana en ocasión del cincuenta aniversario de su tesis doctoral, así como su colaboración con la Societas Hobbesiana, de la cual fue presidente a partir de 1929 . Hobbes nunca le dejó de interesar.

La última etapa vital-intelectual del autor, fue la que transcurrió de 1930 a 1936, y que se desa- rrolla en detalle en el sexto capítulo. La situación en el año 30 en el país es crítica, y Tönnies y su mujer realizan dos actos muy significativos en menos de un mes de diferencia: su baja de la Iglesia protestante debido a su "actitud amistosa" con los nazis (18 de marzo), y afiliación al partido socialdemócrata (1 de abril). Su contribución académica, no obstante, no se resiente y publica en 1931, el artículo La Familia Moderna y la monografía Introducción a la Sociología, que le llevó 8 años, donde presenta la distinción entre sociología pura, aplicada y empírica. Tönnies no sólo sigue activo en faceta académica, sino también en su compromiso práctico. No obstante, en septiembre de 1933, con 78 años de edad, sufre un gran revés, es expulsado de la Universidad de Kiel por su "falta de lealtad con la nación alemana" y se le retira, aunque después se le devuelve, y de forma humillante, su pensión. Hay opciones de emigrar a Estados Unidos o Dinamarca, pero finalmente declina esa opción. Renuncia también a la presidencia de la Sociedad Alemana de Sociología, a favor de Sombart, y se siente decepcionado por la nula resistencia al nuevo régimen por parte de muchos de sus colegas. De nuevo, en una situación crítica, aparece el rigor moral tönnesiano. Erdozáin, desgrana las sensaciones y vivencias de Tönnies hasta el final, y analiza en este capítulo su actitud hacia la muerte, que es aceptada con serenidad y consciencia. Además, percibe el aprecio de sus amigos y discípulos más que nunca, hecho que le alegra el corazón por la importancia dada a la amistad en su vida. Murió, el 9 de abril de 1936 acompañado de su hija Franziska.

Finalmente, el capítulo séptimo, y titulado a Modo de Conclusión, bien podría contestar a la siguiente pregunta ¿Qué recuperamos recuperando a Tönnies? Algunos autores cómo König sugerían que no es necesario salvarlo. Erdozáin, opina todo lo contrario, y lo justifica eruditamente en este último capítulo. Entre otros, destaca que la originalidad de Tönnies recae en la comprensión de lo social, y en el trasfondo de lo social se encuentra en la voluntad, objeto de su sociología. Erdozáin también nos invita a entender a Tönnies, en toda su plenitud, y no solo a través de su obra más distinguida. Tönnies observa la desaparición de 
un mundo antiguo, y la aparición de uno nuevo, lo sufre y lo intenta comprender a partir de no solo una sociología pura, sino también empírica y aplicada. Entender todo el corpus tönnesiano nos puede ayudar a entender la sociedad de hoy. Comprender las ilusiones, frustraciones del sociólogo frisón nos puede ayudar a comprendernos. Y leer obras como la de Erdozáin nos invita a pensar que otra sociología es posible.

Hoy, que vivimos en una etapa de publish and perish, donde escribimos para nuestra microtribu, donde la micro-micro-especialidad produce investigación de alta calidad, pero no necesariamente con sentido, volver a los orígenes no tan lejanos de la sociología, nos puede ayudar a resituándonos, a captar los problemas sociales reales, a buscar nuevas maneras de entender la realidad bajo la luz del conocimiento previo de los grandes maestros, y apuntar hacia una sociología más reflexiva, profunda, abierta y con sentido.

Marc Grau-Grau received a PhD in Social Policy from the University of Edinburgh. He has obtained a MBA from ESADE Business School and a MA in Political and Social Sciences from University Pompeu Fabra in Barcelona, Spain. He is a Research Fellow at Harvard Kennedy School and a researcher at Universitat International de Catalunya, Spain. His research interests focus on work-family balance, gender equality, fatherhood involvement and flexible policies. He is a co-editor of the book: The Work-Family Balance in Light of Technology, and Globalization. 